\title{
Ampliação do Canal do Panamá
}

\section{Andréa Benetti Carvalho de Oliveira1}

\section{RESUMO}

Após dez anos de jurisdição e administração panamenha no Canal do Panamá debate-se hoje sobre sua ampliação.

Palavras-chave: Panamá; Canal do Panamá; Ampliação; Histórico.

Principal canal de comunicação entre os oceanos Atlântico e Pacífico, facilitador de intercâmbio comercial entre Ásia, Europa e Américas, o Canal Interoceânico do Panamá, cuja construção iniciou-se em 1881, é de inteira administração e responsabilidade do Estado que o nomeia há apenas pouco mais de 10 anos - 14 de dezembro de 1999. Após dez anos de plena jurisdição e administração panamenha, um balanço dos avanços e das dificuldades já pode ser feito, ainda que brevemente.

O Departamento do Istmo, região onde hoje se encontra o Panamá, foi criado ainda quando pertencente à Colômbia, com o objetivo de atender aos anseios comerciais e estratégicos de ligação entre os dois oceanos já referidos. Em 1878, a Colômbia autorizou a França a iniciar projetos e obras de formação de um canal ístmico, a cargo da Companhia Universal Interoceânica, de Ferdinand de Lesseps - engenheiro que havia concluído as obras do Canal de Suez em 1869.

Onze anos depois, em 1889, a empresa francesa quebrou e os Estados Unidos compraram, aproximadamente, 10 milhas de terras na região escavada, a fim de assumir a obra. Assim, novas negociações, para conclusão da obra, foram realizadas, desta vez entre Colômbia e Estados Unidos, os quais não aceitaram as condições impostas pelo Estado territorial. Tal situação fomentou a rebelião na região, que, mais tarde, resultaria

\footnotetext{
1 Mestre pelo Programa de Pós-Graduação em Ciência Política na UFPR e pesquisadora dos Núcleos de Pesquisa em Relações Internacionais e em Direito Internacional Público do MERCOSUL, ambos da UFPR. 
na separação da República do Panamá do restante daquele país, em 3 de novembro de 1903.

Neste mesmo ano, duas semanas depois, em 18 de novembro de 1903, foi assinado o Tratado HayBunau-Varilla, o qual concedeu aos EUA perpetuamente o uso, a ocupação e o controle da zona de extensão de mais de 10 milhas em torno do canal, assim como autorizava a presença militar estadunidense, constante na região. Em que pese constantes apelos do governo local para revisão das cláusulas contratuais, apenas em 1977 foi estabelecido novo regime convencional.

Os Tratados de 1974 e 1977, conhecidos como Torrijos-Carter, os quais dispõem sobre o Canal do Panamá e sobre a Neutralidade Permanente e o Funcionamento do Canal, foram assinados em 7 de setembro deste ano, tendo entrado em vigor logo em 1ำ de outubro de 1979. Pelas cláusulas pactuadas, a gestão do canal seria gradativamente transferida ao Panamá, o qual seria plenamente competente, jurisdicional e administrativamente, a partir de 31 de dezembro de 1999. No entanto, a cerimônia fora adiantada para 14 de dezembro deste ano. Dessa forma, o Panamá readquire o exercício de sua soberania local, incluindo seus portos e sua estrada de ferro interoceânica, permanecendo os Estados Unidos na defesa militar local até o final do ano de 1999. A partir de 2000, aplica-se o princípio geral da neutralidade no Canal - em verdade, neutralização - a qual deve ser defendida pelos EUA, inclusive contra eventual intervenção panamenha (DINH; DAILLIER; PELLET, 2003, p. 1252).

Hoje, sob a responsabilidade do Panamá, a Autoridad del Canal de Panamá ACP, responsável pela administração do canal ístmico, em apenas dez anos, já investiu significativamente em infraestrutura local, com ampliação da capacidade de passagem, reabilitação dos rios e mananciais no entorno, modernização das eclusas e, até mesmo, elaborou um projeto - ainda polêmico - de construção de um terceiro jogo de eclusas com ampliação do Canal. A reversão do Canal do Panamá não implica apenas mera administração local, mas também em desafios ante, sobretudo, o aumento dos fluxos de navegação comercial, turística marítimos.

Dentre os desafios, hoje, o mais substantivo é a questão sobre a construção do terceiro jogo de eclusas, prevista no Plano Estratégico de 2005-2015 e elaborada pela ACP, cujos objetivos principais são: o aumento da renda nacional (uma vez que aportes significativos ao Tesouro do país decorrem do trânsito de navios no istmo); a melhoria 
da competitividade internacional do canal (hoje já existem navios que extrapolam as dimensões máximas permitidas de trafegabilidade) e os ganhos de produtividade, segurança e eficiência no Canal.

Dessa forma, o terceiro jogo de eclusas compreende a construção de dois complexos, um no Pacífico e outro no Atlântico, com reaproveitamento de água e aumento da capacidade de elevação do nível máximo de funcionamento do lago Gatún. Prevê-se, assim, um aumento no tráfego de 280 milhões de toneladas $\mathrm{CPSUAB}^{2}$ anuais para 510 milhões de toneladas CPSUAB, após concluídas as obras.

A ampliação foi referendada em 2006 pela população local (76,8\% dos votos), com custo estimado em US\$ 5,2 bilhões, e serve como exemplo de projeto transparente e que procura equacionar perdas ambientais mínimas com ganhos sociais e benefícios econômicos locais. Sua inauguração está prevista para o ano de 2014, com pleno funcionamento a partir de 2015.

\section{Referências Bibliográficas}

AUTORIDADE DEL CANAL DE PANAMÁ. Disponível em: http://www.pancanal.com. Acesso em: janeiro de 2010.

DINH, Nguyen Quoc; DAILLIER, Patrick; PELLET, Alain. Direito Internacional Público. $2^{\underline{a}}$ ed.. Lisboa: Fundação Calouste Gulbenkian, 2003.

DONGHI, Túlio Halperin. História da América Latina. Rio de Janeiro: Paz e Terra, 1975.

REPÚBliCA DE PANAMÁ. Disponível em: http://www.pa/index.html. Acesso em: janeiro de 2010 .

REPÚBLICA DE PANAMÁ; UNITED STATES OF AMERICA. Tratados Torrijos-Carter: Tratado del Canal de Panamá y Tratado Concerniente a la Neutralidad Permanente

\footnotetext{
2 CPSUAB é a medida utilizada, pelo canal, para cálculo de pedágio, significa Canal de Panamá - Sistema Universal de Arqueo de Buques. Uma tonelada CPSUAB equivale a aproximadamente 100 pés cúbicos de carga.

Conjuntura Global, Curitiba, Vol. 1, n.1, jul./set., 2012, p. 3-6. 
del Canal y al Funcionamiento del Canal de Panamá, entre la República de Panamá y los Estados Unidos. Washington, 7 de septiembre of 1977.

UNIVERSIDADE FEDERAL DO PARANÁ. Sistema de Bibliotecas. Redação e editoração. Curitiba: Editora UFPR, 2000. (Normas para apresentação de documentos científicos, 9v.).

VILLA, Rafael Duarte; CORDEIRO, Fábio Cereda. Ganhos relativos ou política doméstica? Os tratados do Canal do Panamá como um jogo de dois níveis. Contexto Internacional, Rio de Janeiro, vol. 28, n. 2, p. 301-353, 2006.-222, 2000. 